Tohoku J. exp. Med., 1981, 133, 33-43

\title{
Bacteriocin (Marcescin) Typing of Glinically Isolated Serratia marcescens
}

\author{
Masaru Nasu \\ Department of Laboratory Medicine, Nagasaki University \\ Hospital, Nagasaki 852
}

\begin{abstract}
Nasu, M. Bacteriocin (Marcescin) Typing of Clinically Isolated Serratia marcescens. Tohoku J. exp. Med., 1981, 133 (1), 33-43 — A study of bacteriocin (marcescin) typing was carried out by an agar cross streaking method (without any induction reagent) with 654 strains of Serratia marcescens recently isolated from clinical materials in Nagasaki University Hospital. In a complete checker-board experiment with 80 strains on bacteriocin production and sensitivity, 43 strains $(54 \%)$ were productive, $74(93 \%)$ were sensitive and 4 $(5 \%)$ were negative. Immunity was confirmed in all strains. Eight out of 80 strains of Serratia marcescens were selected as indicators in order to achieve the best differentiation of strains in bacteriocin typing, and 654 strains were classified into 30 types by bacteriocin production typing and into 49 types by bacteriocin sensitivity typing; the former showed more stable results than the latter in reproducibility. Bacteriocins produced by this method were considered to be high molecular, phage tail-like group A bacteriocins reported by Prinsloo (1966). Bacteriocin production typing was more useful for classification and subdivision of strains than serotyping (0-group).—Serratia marcescens; bacteriocin; bacteriocin typing
\end{abstract}

Bacteriocins are bactericidal proteins which are synthesized by bacteria, and inhibit the growth of other strains of the same species or closely related species (Reeves 1965; Nomura 1967). The bacteriocins produced by Serratia marcescens (S. marcescens) were first described by Fuller and Horton (1950), and named marcescins. They reported that marcescins were polypeptides which inhibited the growth of Corynebacterium diphtheriae and Staphylococcus aureus. Hamon and Péron (1961) reported the bactericidal activity of marcescins among the same species of $S$. marcescens. Prinsloo (1966) demonstrated in her study of bacteriocin activity of 139 strains of $S$. marcescens that marcescins include two types of bacteriocins; group A bacteriocins are mainly active against $S$. marcescens, some strains of Salmonella and Escherichia coli, and are resistant to trypsin, heat and chloroform; group B bacteriocins are inactive against $S$. marcenscens, but are active against Escherichia coli, Aerobacter aerogenes and Hafnia, and are sensitive to trypsin, heat and chloroform. Furthermore she divided group A bacteriocins into 8 groups.

Received for publication, December 6, 1979.

Request for reprints should be addressed to Dr. Masaru Nasu, Department of Laboratory Medicine, Nagasaki University Hospital, 7-1, Sakamoto-machi, Nagasaki 852, Japan. 
In recent years, the incidence of $S$. marcescens isolation from clinical specimens has been increasing (Davis et al. 1970; Nasu et al. 1977), and the problems of nosocomial infections or opportunistic infections due to $S$. marcescens have become very serious (Editorial 1977; Yu 1979).

For the purpose of epidemiological studies on the distribution of $S$. marcescens and on the infections caused by this organism in the hospital, Farmer (1972a, b), Traub et al. (1971), and Traub and Raymond (1971) investigated some methods for bacteriocin typing of $S$. marcescens using a broth culture medium with mitomycin C for inducing the bacteriocins. Recently Anderhub et al. (1977) reported a crossstreaking method of bacteriocin typing using an agar medium without induction. Independently, Nasu (1977) studied the bacteriocin production and sensitivity of $S$. marcescens strains isolated from clinical specimens in Nagasaki University Hospital using an agar plate medium without induction, and tried to classify many strains of $S$. marcescens by bacteriocin typing.

This article describes the method for typing S. marcescens as an epidemiological marker and presents the results.

\section{Materials and Methods}

Bacteria. Six hundred and fifty-four strains of S. marcescens, 273 strains of the family Enterobacteriaceae, 19 strains of Aeromonas hydrophila and 121 strains of glucose non-fermentative gram negative bacilli were obtained from various clinical specimens in the Department of Laboratory Medicine, Division of Bacteriology, Nagasaki University Hospital during the period from April 1970 to May 1979. These strains were identified according to the manual of Cowan (1974) and Bergey's manual (Buchanan and Gibbons 1974). Each strain was inoculated into a sterilized tube with a rubber stopper containing $3 \mathrm{ml}$ of the following medium: Bacto-casitone (Difeo) $10 \mathrm{~g}$, yeast extract (Difeo) $3 \mathrm{~g}, \mathrm{NaCl} 5 \mathrm{~g}$, and Bacto-agar (Difco) $3 \mathrm{~g}$ were dissolved in 1,000 $\mathrm{ml}$ of distilled water and adjusted to $\mathrm{pH}$ 7.2. The strains were incubated at $37^{\circ} \mathrm{C}$ overnight and stored at room temperature in the dark. Subculture was carried out about once a year.

Bacteriocin production and sensitivity. The procedure for bacteriocin production and sensitivity assay was carried out by the agar cross streaking method according to the colicine typing technique of Abbott and Shannon (1958) or the pyocine typing technique of Gillies and Govan (1966). A bacteriocin producing strain previously cultured at $37^{\circ} \mathrm{C}$ overnight in Trypticase soy broth (TSB, BBL) was streaked diametrically across a plate of thick DST agar (8-10 $\mathrm{mm}$ deep, Oxoid) in a width of about $1 \mathrm{~cm}$. After incubation for $48 \mathrm{hr}$ at $30^{\circ} \mathrm{C}$, the macroscopic growth was removed with a glass slide and the plate was exposed to chloroform vapour for $1 \mathrm{hr}$ to kill the organisms. The plate was kept open for $1 \mathrm{hr}$ at room temperature and any traces of chloroform vapour were eliminated. The bacteriocin sensitive strains previously cultivated in TSB for $3-4 \mathrm{hr}$ at $37^{\circ} \mathrm{C}$ were streaked on the chloroform treated medium at a right angle to the line of the original inoculum and the plate was left at $4^{\circ} \mathrm{C}$ overnight or at least for $4 \mathrm{hr}$. After reincubation for $18-20 \mathrm{hr}$ at $30^{\circ} \mathrm{C}$, the plate was examined for evidence of growth inhibition of the bacteriocin sensitive strains.

Indicator strains of bacteriocin typing. Out of 80 strains of $S$. marcescens tested reciprocally by the above method in bacteriocin production and sensitivity, 8 strains (Nos. 3, 16, 33, 52, 53, 70, 78 and 79) were chosen as the indicators which gave the best differentiation, and typing of 654 strains of $S$. marcescens was then carried out using these indicators.

Bacteriocin preparations. Five bacteriocin producing strains, Nos. $16,33,52,53$ and 78 , were inoculated into tubes containing $3 \mathrm{ml}$ of TSB separately and incubated at $30^{\circ} \mathrm{C}$ for 
$24 \mathrm{hr}$. Then, $0.3 \mathrm{ml}$ of chloroform (Wako Pure Chemical Co., Osaka) was added to each tube. The tubes were shaken vigorously 30 times and left standing for $1 \mathrm{hr}$ at room temperature. Then tubes were centrifuged at $1,400 \times \mathrm{g}$ for $30 \mathrm{~min}$, and the chloroform-free supernatants were taken as crude bacteriocin preparations.

Trypsin sensitivity. A 3\% solution of trypsin (1:250, Difco) in phosphate buffer $\mathrm{pH}$ 7.2 was used for the trypsin sensitivity test; $0.2 \mathrm{ml}$ of trypsin solution was added to each tube containing $1 \mathrm{ml}$ of the bacteriocin preparation. The tubes were incubated at $37^{\circ} \mathrm{C}$ for $30 \mathrm{~min}$, after which $0.2 \mathrm{ml}$ of chloroform was added to each tube and treated as described above.

Heat sensitivity. Each tube containing $1 \mathrm{ml}$ of the bacteriocin preparation was heated at $56^{\circ} \mathrm{C}$ for $30 \mathrm{~min}$ in a water bath. After adding $0.2 \mathrm{ml}$ of chloroform to each tube, they were treated as described above.

The trypsin-treated, the heat-treated and the chloroform-treated bacteriocin preparation were diluted two-fold with phosphate buffer ( $\mathrm{pH}$ 7.2), and examined for activity against appropriate indicator strains of S. marcescens by means of the so-called "spotting method".

Serotyping of S. marcescens. Serotyping of S. marcescens was carried out by the tube agglutination method.

\section{Results}

Bacteriocin production and sensitivity tests on 80 strains of $S$. marcescens by a checker-board technique. Eighty out of 654 strains excluding the strains reisolated from the same patient were tested by the agar cross streaking method, and the results are shown in Table 1. Forty-three strains (54\%) out of the 80 tested were bacteriocin-producers and $74(93 \%)$ were sensitive to the bacteriocins of $S$. marcescens; of 42 pigment producing strains, $21(50 \%)$ were producers and all were sensitive; of 38 pigment non-pigment producing strains, $22(58 \%)$ were producers and $32(84 \%)$ were sensitive. Four strains $(5 \%)$ did not react at all; they were non-pigment producing ones. Immunity was confirmed in all strains tested.

TABLE 1. Result of marcescin production and sensitivity of 80 Serratia marcescens strains including 42 pigment producing and 38 non-pigment producing strains

\begin{tabular}{cccr}
\hline \multicolumn{2}{c}{ Marcescin } & & \\
Production & Sensitivity & Number of strains & Percent \\
\hline+ & + & $41(21)^{*}$ & $51(50)$ \\
+ & - & $2(0)$ & $3(0)$ \\
- & + & $33(21)$ & $41(50)$ \\
- & - & $4(0)$ & $5 \quad(0)$ \\
\hline
\end{tabular}

* Figures in parentheses show the number of pigment producing strains.

Reproducibility of bacteriocin production test. The checker-board experiment was carried out using 8 indicators 3 times every third week and the results obtained are shown in Table 2. S. marcescens No. 3, No. 70 and No. 78 showed variable results in bacteriocin production against the sensitive strain No. 53 or No. 70. However, the same results were obtained in 2 out of 3 repeated experiments. 
TABLE 2. Reproducibility of marcescin production and sensitivity pattern of 8 Serratia marcescens strains*

\begin{tabular}{|c|c|c|c|c|c|c|c|c|c|}
\hline \multirow{2}{*}{$\begin{array}{c}\text { Marcescin } \\
\text { sensitive } \\
\text { strain }\end{array}$} & \multicolumn{9}{|c|}{ Marcescin producing strain } \\
\hline & No. 3 & No. 16 & No. $3:$ & & No. 52 & No. 53 & No. 70 & No. 78 & No. 79 \\
\hline No. 3 & --- & --- & - - & - & +++ & +++ & --- & +++ & -- \\
\hline No. 16 & --- & --- & -- & - & --- & $++t$ & --- & --- & --- \\
\hline No. 33 & --- & --- & - - & - & $--\cdots$ & +++ & --- & --- & --- \\
\hline No. 52 & --- & --- & ++ & + & $-\quad-$ & --- & --- & --- & --- \\
\hline No. 53 & -+- & +++ & ++ & + & +++ & --- & -+- & +++ & --- \\
\hline No. 70 & --- & --- & -- & - & --- & +++ & --- & ++- & --- \\
\hline No. 78 & --- & --- & -- & - & --- & +++ & --- & --- & --- \\
\hline No. 79 & --- & +++ & ++ & + & $++t$ & +++ & --- & --- & --- \\
\hline
\end{tabular}

* The test was carried out 3 times every third week using DST agar.

Effect of culture media, temperature and incubation time on bacteriocin production. The checker-board experiment was carried out using 8 indicators under the following conditions. Of 5 culture media, DST agar, Heart Infusion agar (BBL), Nutrient agar (Difco), Trypticase soy agar (BBL) and Colicine typing agar (Eiken, Japan), the clearest zones of growth inhibition were observed on Heart Infusion agar and Colicine typing agar, while Nutrient agar gave the poorest results. Bacteriocin production was greater at $30^{\circ} \mathrm{C}$ than $37^{\circ} \mathrm{C}$. No differences were noted in bacteriocin production at 24,48 and $72 \mathrm{hr}$ at $30^{\circ} \mathrm{C}$, although there were some differences in the clarity of zones of growth inhibition.

Sensitivity to chloroform, trypsin and heat. The results obtained are shown in Table 3. The bacteriocin preparations from 4 strains of $S$. marcescens were tolerant to all three treatments. The bacteriocin activity of S. marcescens No. 53

TABLE 3. Tolerance of bacteriocin produced by Serratia marcescens to chloroform, heat* and trypsin

\begin{tabular}{|c|c|c|c|c|c|c|c|c|c|c|c|c|c|}
\hline \multirow{2}{*}{$\begin{array}{l}\text { Bacteriocin } \\
\text { producing } \\
\text { strain }\end{array}$} & \multirow{2}{*}{$\begin{array}{c}\text { Bacteriocin } \\
\text { sensitive } \\
\text { strain }\end{array}$} & & \multicolumn{11}{|c|}{ Dilution titer } \\
\hline & & & $2^{0}$ & $2^{1}$ & $2^{2}$ & $2^{3}$ & $2^{4}$ & $2^{5}$ & $2^{6}$ & $2^{7}$ & $2^{8}$ & $2^{9}$ & $2^{10}$ \\
\hline \multirow[t]{3}{*}{ No. 16} & \multirow[t]{3}{*}{ No. 53} & Chloroform & H & H & $H$ & H & + & \pm & - & - & - & - & - \\
\hline & & Heat & H & H & H & $H$ & + & \pm & - & - & - & - & - \\
\hline & & Trypsin & H & H & H & $H$ & + & \pm & - & - & - & - & - \\
\hline \multirow[t]{3}{*}{ No. 33} & \multirow[t]{3}{*}{ No. 53} & Chloroform & H & H & H & H & H & + & \pm & - & - & - & - \\
\hline & & Heat & H & H & H & H & H & + & \pm & - & - & - & - \\
\hline & & Trypsin & H & H & H & H & H & + & \pm & - & - & - & - \\
\hline \multirow[t]{3}{*}{ No. 52} & \multirow[t]{3}{*}{ No. 53} & Chloroform & H & H & H & H & + & + & + & - & - & - & - \\
\hline & & Heat & $H$ & $H$ & $H$ & H & + & \pm & - & - & - & - & - \\
\hline & & Trypsin & H & H & H & H & H & + & \pm & - & - & - & - \\
\hline \multirow[t]{3}{*}{ No. 53} & \multirow[t]{3}{*}{ No. 33} & Chloroform & H & H & H & $H$ & + & + & \pm & - & - & - & - \\
\hline & & Heat & - & - & - & - & - & - & - & - & - & - & - \\
\hline & & Trypsin & H & $H$ & H & H & H & + & \pm & - & - & - & - \\
\hline \multirow[t]{3}{*}{ No. 78} & \multirow[t]{3}{*}{ No. 53} & Chloroform & H & H & $H$ & + & + & + & \pm & - & - & - & - \\
\hline & & Heat & H & H & $H$ & H & + & + & \pm & - & - & - & - \\
\hline & & Trypsin & H & $H$ & H & + & + & \pm & \pm & - & - & - & - \\
\hline
\end{tabular}

* The supernatant of the culture broth was incubated at $56^{\circ} \mathrm{C}$ for $30 \mathrm{~min}$. 
was lost by heating but was tolerant to trypsin or chloroform treatment.

Bacteriocin activity against other genera of bacteria. Table 4 shows the range of bacteriocin activity of 4 strains of $S$. marcescens against 654 of the same species and 417 strains of other species by the agar cross streaking method. The bacteriocin produced by $S$. marcescens No. 52 was only active against the same species. The bacteriocins produced by S. marcescens No. 53 and No. 78 were active for some Escherichia coli, Klebsiella aerogenes, Enterobacter aerogenes and Enterobacter cloacae strains, and that of S. marcescens No. 33 was active for some Citrobacter freundii, Enterobacter cloacae, Proteus inconstans and Aeromanas hydrophila strains as well. None of the bacteriocins tested were active for 121 strains of glucose non-fermentative gram negative bacilli.

TABLE 4. Marcescin activity to gram-negative rods isolated from clinical materials

\begin{tabular}{|c|c|c|c|c|c|c|c|c|c|}
\hline \multirow{3}{*}{ Strain tested } & \multirow{3}{*}{$\begin{array}{c}\text { Number } \\
\text { of } \\
\text { strains }\end{array}$} & \multicolumn{8}{|c|}{ Marcescin producer } \\
\hline & & \multicolumn{2}{|c|}{ No. 33} & \multicolumn{2}{|c|}{ No. 52} & \multicolumn{2}{|c|}{ No. 53} & \multicolumn{2}{|c|}{ No. 78} \\
\hline & & $\begin{array}{c}\text { Inhibi- } \\
\text { tion }\end{array}$ & $\%$ & $\begin{array}{c}\text { Inhibi- } \\
\text { tion }\end{array}$ & $\%$ & $\begin{array}{l}\text { Inhibi- } \\
\text { tion }\end{array}$ & $\%$ & $\begin{array}{c}\text { Inhibi- } \\
\text { tion }\end{array}$ & $\%$ \\
\hline Citrobacter freundii & 40 & 4 st. & 10 & 0st. & 0 & 0 st. & 0 & 0 st. & 0 \\
\hline Escherichia coli & 40 & 0 & 0 & 0 & 0 & 3 & 8 & 0 & 0 \\
\hline Klebsiella aerogenes & 30 & 0 & 0 & 0 & 0 & 2 & 7 & 0 & 0 \\
\hline Enterobacter aerogenes & 30 & 0 & 0 & 0 & 0 & 4 & 13 & 0 & 0 \\
\hline Enterobacter cloacae & 30 & 5 & 17 & 0 & 0 & 12 & 40 & 1 & 3 \\
\hline Serratia marcescens & 654 & 334 & 51.1 & 293 & 44.8 & 449 & 68.7 & 99 & 15.1 \\
\hline Proteus mirabilis & 20 & 0 & 0 & 0 & 0 & 0 & 0 & 0 & 0 \\
\hline Proteus vulgaris & 20 & 0 & 0 & 0 & 0 & 0 & 0 & 0 & 0 \\
\hline Proteus morganii & 24 & 0 & 0 & 0 & 0 & 0 & 0 & 0 & 0 \\
\hline Proteus rettgeri & 22 & 0 & 0 & 0 & 0 & 0 & 0 & 0 & 0 \\
\hline Proteus inconstans & 17 & 1 & 6 & 0 & 0 & 0 & 0 & 0 & 0 \\
\hline Aeromonas hydrophila & 19 & 4 & 21 & 0 & 0 & 0 & 0 & 0 & 0 \\
\hline Pseudomonas aeruginosa & 40 & 0 & 0 & 0 & 0 & 0 & 0 & 0 & 0 \\
\hline Pseudomonas putida & 27 & 0 & 0 & 0 & 0 & 0 & 0 & 0 & 0 \\
\hline Pseudomonas maltophilia & 21 & 0 & 0 & 0 & 0 & 0 & 0 & 0 & 0 \\
\hline Pseudomonas putrefaciens & 8 & 0 & 0 & 0 & 0 & 0 & 0 & 0 & 0 \\
\hline Moraxella phenylpyrubica & 4 & 0 & 0 & 0 & 0 & 0 & 0 & 0 & 0 \\
\hline Acinetobacter calcoaceticus & 21 & 0 & 0 & 0 & 0 & 0 & 0 & 0 & 0 \\
\hline
\end{tabular}

Bacteriocin (marcescin) typing of S. marcescens. Bacteriocin typings of 654 strains of $S$. marcescens including one bacteriocin producing typing and one sensitivity typing, were subjected to the agar cross streaking method using 8 indicators, and the strains tested were coded in growth inhibition patterns respectively. The results obtained are shown in Tables 5 and 6 . By bacteriocin production typing, it was shown that the strains were classified into 30 types, including one type with no bacteriocin activity (type P-0), 352 strains $(53.8 \%$ ) were included in type $\mathrm{P}-0$, followed by $57(8.7 \%)$ in $\mathrm{P}-12,51(7.8 \%)$ in $\mathrm{P}-10,42(6.4 \%)$ in $\mathrm{P}-15,35(5.4 \%)$ in $\mathrm{P}-9,20(3.1 \%)$ in $\mathrm{P}-1$, and so on in order. By bacteriocin 
TABLE 5. Distribution of 654 Serratia marcescens strains by marcescin production pattern

\begin{tabular}{|c|c|c|c|c|c|c|c|c|c|c|}
\hline \multirow{2}{*}{$\begin{array}{c}\text { Marcescin } \\
\text { production } \\
\text { pattern }\end{array}$} & \multicolumn{8}{|c|}{ Indicator strain } & \multirow{2}{*}{$\begin{array}{c}\text { Number of } \\
\text { strains }\end{array}$} & \multirow{2}{*}{$\begin{array}{c}\text { Number of } \\
\text { patients }\end{array}$} \\
\hline & No. 3 & 16 & 33 & 52 & 53 & 70 & 78 & 79 & & \\
\hline P- 0 & - & - & - & - & - & - & - & - & $352(53.8)$ & $221(51.6)$ \\
\hline 1 & + & + & + & - & - & + & + & + & $20(3.1)$ & $16(2.3)$ \\
\hline 2 & + & + & + & - & + & + & + & - & 1 & 1 \\
\hline 3 & - & + & + & + & + & - & - & + & 1 & 1 \\
\hline 4 & - & + & + & - & - & - & + & - & 3 & 3 \\
\hline 5 & + & - & - & - & + & + & - & - & 7 & 6 \\
\hline 6 & - & - & - & + & + & - & - & + & $18(2.8)$ & $12(2.8)$ \\
\hline 7 & - & - & - & + & + & - & + & - & 1 & 1 \\
\hline 8 & - & - & - & - & + & - & + & + & 4 & 4 \\
\hline 9 & - & - & - & - & + & - & + & - & $35(5.4)$ & $27(6.3)$ \\
\hline 10 & - & - & - & - & + & - & - & + & $51(7.8)$ & $26(6.1)$ \\
\hline 11 & - & + & - & - & + & - & - & - & 1 & 1 \\
\hline 12 & - & - & - & - & + & - & - & - & $57(8.7)$ & $38(8.9)$ \\
\hline 13 & - & - & - & + & - & - & - & - & $21(3.2)$ & $18(4.2)$ \\
\hline 14 & - & - & - & - & - & - & + & - & 5 & 4 \\
\hline 15 & - & - & - & - & - & - & - & + & $42(6.4)$ & $21(4.9)$ \\
\hline 16 & - & - & + & + & + & - & - & + & 1 & 1 \\
\hline 17 & + & - & + & - & + & - & + & - & 1 & 1 \\
\hline 18 & - & - & + & + & - & - & - & - & 1 & 1 \\
\hline 19 & + & - & - & - & + & - & + & - & $10(1.5)$ & 9 \\
\hline 20 & - & + & + & - & + & - & - & + & 1 & 1 \\
\hline 21 & + & + & + & - & - & - & + & + & 4 & 1 \\
\hline 22 & + & - & - & + & + & - & + & - & 1 & 1 \\
\hline 23 & + & - & - & - & - & - & - & - & 1 & 1 \\
\hline 24 & + & - & - & - & + & - & - & - & 4 & 3 \\
\hline 25 & + & - & - & - & + & - & - & + & 1 & 1 \\
\hline 26 & - & - & - & + & + & - & - & - & 2 & 2 \\
\hline 27 & + & - & - & + & - & - & - & - & 1 & 1 \\
\hline 28 & + & + & + & - & - & + & + & - & 6 & 4 \\
\hline \multirow[t]{2}{*}{29} & + & - & - & - & - & + & + & - & 1 & 1 \\
\hline & \multicolumn{8}{|c|}{ Total } & $654(100)$ & $428(100)$ \\
\hline
\end{tabular}

+ , inhibition; -, no inhibition.

Figures in parentheses indicate percent of total number.

sensitivity typing, 654 strains of $S$. marcescens were classified into 49 patterns including one type with no bacteriocin susceptibility (type S-0); 161 stains $(24.6 \%)$ of them were distributed in S-20, followed by $155(23.7 \%)$ in $\mathrm{S}-3,79(12.1 \%)$ in $\mathrm{S}-0,32(4.9 \%)$ in $\mathrm{S}-21$, and so on in order.

Relationship of bacteriocin production typing and serotyping (0-group). Table 7 shows the relationship of bacteriocin production typing and serotyping in 512 strains of $S$. marcescens tested. In serotyping, most of them were distributed among types $0-17(34.4 \%)$ and $0-8(27.1 \%)$. They were classified into many types by bacteriocin production typing, and 176 strains of $S$. marcescens which were classified into serotype $0-17$ distributed mainly in type $\mathrm{P}-0$ in bacteriocin production typing. 
TABLE 6. Distribution of 654 Serratia marcescens strains by marcescin sensitivity pattern

\begin{tabular}{|c|c|c|c|c|c|c|c|c|c|}
\hline \multirow{2}{*}{$\begin{array}{l}\text { Marcescin } \\
\text { sensitivity } \\
\text { pattern }\end{array}$} & \multicolumn{8}{|c|}{ Indicator strain } & \multirow{2}{*}{$\begin{array}{c}\text { Number of } \\
\text { strains }\end{array}$} \\
\hline & No. 3 & 16 & 33 & 52 & 53 & 70 & 78 & 79 & \\
\hline S- 0 & - & - & - & - & - & - & - & - & $79(12.1)$ \\
\hline 1 & + & + & + & + & - & + & - & - & 3 \\
\hline 2 & - & + & + & + & + & - & + & - & $21(3.2)$ \\
\hline 3 & - & + & + & + & + & - & - & - & $155(23.7)$ \\
\hline 4 & - & + & + & + & - & - & + & - & 5 \\
\hline 5 & + & - & + & - & + & + & - & - & 2 \\
\hline 6 & - & - & + & + & + & - & + & - & 1 \\
\hline 7 & - & - & + & + & + & - & - & - & $11(1.7)$ \\
\hline 8 & + & - & - & - & + & + & - & - & $10(1.5)$ \\
\hline 9 & - & + & - & + & + & - & - & - & 2 \\
\hline 10 & - & - & - & + & + & - & + & - & 6 \\
\hline 11 & - & - & + & - & + & - & + & - & 1 \\
\hline 12 & + & - & + & - & + & - & - & - & 1 \\
\hline 13 & - & - & + & - & + & - & - & - & $13(2.0)$ \\
\hline 14 & - & - & - & - & + & - & + & - & 6 \\
\hline 15 & - & - & - & + & - & - & + & - & 4 \\
\hline 16 & + & - & - & - & + & - & - & - & 2 \\
\hline 17 & - & - & - & + & + & - & - & - & $25(3.8)$ \\
\hline 18 & - & - & - & - & + & + & - & - & $10(1.5)$ \\
\hline 19 & - & - & + & - & - & - & - & - & $14(2.1)$ \\
\hline 20 & - & - & - & - & + & - & - & - & $161(24.6)$ \\
\hline 21 & - & - & - & - & - & - & + & - & $32(4.9)$ \\
\hline 22 & + & - & + & - & - & + & - & - & 1 \\
\hline 23 & + & + & + & + & - & - & + & - & 2 \\
\hline 24 & - & + & + & + & - & - & - & - & $11(1.7)$ \\
\hline 25 & + & + & + & - & - & + & + & - & 2 \\
\hline 26 & - & + & + & - & - & + & + & - & 1 \\
\hline 27 & + & - & - & - & - & + & - & - & 1 \\
\hline 28 & + & + & + & - & - & - & - & - & 2 \\
\hline 29 & - & - & + & + & + & + & - & - & $13(2.0)$ \\
\hline 30 & + & - & + & + & + & + & - & - & 2 \\
\hline 31 & - & + & + & - & - & - & - & - & 3 \\
\hline 32 & + & + & + & + & - & + & + & - & $13(2.0)$ \\
\hline 33 & + & - & + & + & - & + & - & - & 1 \\
\hline 34 & - & - & + & + & - & + & - & - & 2 \\
\hline 35 & + & - & - & + & + & + & - & - & 1 \\
\hline 36 & + & + & + & - & - & - & + & - & 1 \\
\hline 37 & - & + & + & - & + & + & - & - & 1 \\
\hline 38 & - & + & + & + & + & + & - & - & 2 \\
\hline 39 & - & - & + & + & - & - & - & - & 1 \\
\hline 40 & - & + & + & + & + & + & + & - & 2 \\
\hline 41 & - & + & + & + & - & + & + & - & 1 \\
\hline 42 & - & - & - & - & - & + & - & - & $12(1.8)$ \\
\hline 43 & - & + & + & + & - & + & - & - & 7 \\
\hline 44 & - & + & - & - & + & - & - & - & 1 \\
\hline 45 & - & - & + & + & - & - & - & - & 1 \\
\hline 46 & - & - & + & - & - & + & - & - & 4 \\
\hline 47 & - & + & + & - & - & - & + & - & 1 \\
\hline \multirow[t]{2}{*}{48} & + & + & + & + & - & - & - & - & 1 \\
\hline & \multicolumn{8}{|c|}{ Total } & $654(100)$ \\
\hline
\end{tabular}

+ , inhibition; - , no inhibition.

Figures in parentheses indicate percent of total number. 
TABLE 7. Relationship between marcescin production pattern and serotype of 512 Serratia marcescens strains

\begin{tabular}{|c|c|c|c|c|c|c|c|c|c|c|c|c|c|c|c|c|c|}
\hline \multirow{2}{*}{$\begin{array}{c}\text { Marcescin } \\
\text { production } \\
\text { pattern }\end{array}$} & \multicolumn{15}{|c|}{ Serotype } & \multirow{2}{*}{$\mathrm{R}^{*}$} & \multirow{2}{*}{ Total } \\
\hline & $0-1$ & $0-3$ & $0-4$ & $0-5$ & $0-6$ & $0-8$ & $0-9$ & $0-10$ & $0-11$ & $0-12$ & $0-13$ & $0-14$ & $0-16$ & $0-17$ & uc & & \\
\hline $\mathrm{P}-0$ & 1 & 3 & 6 & 13 & 3 & 27 & 2 & 1 & 2 & 9 & 1 & 8 & & 157 & 6 & 44 & 283 \\
\hline 1 & & 15 & & & & 2 & & & & & & & & & & 3 & 20 \\
\hline 2 & & & 1 & & & & & & & & & & & & & & 1 \\
\hline 3 & & & & & & 1 & & & & & & & & & & & 1 \\
\hline 4 & & & & & 1 & 1 & & & & & & & & & & & 2 \\
\hline 5 & & & & & & 4 & & & & & & & & 1 & 1 & & 6 \\
\hline 6 & & & 1 & & & 6 & 1 & & & 2 & 1 & 3 & & & 1 & 1 & 16 \\
\hline 7 & & & & 1 & & & & & & & & & & & & & 1 \\
\hline 8 & & & & & & 1 & & & & & & 1 & & & 1 & 2 & 5 \\
\hline 9 & & & & & & 31 & & & & & & & & 1 & & 2 & 34 \\
\hline 10 & & 1 & & & & 10 & & & & & 2 & 1 & & 3 & 3 & 4 & 24 \\
\hline 11 & & & & & & 1 & & & & & & & & & & & 1 \\
\hline 12 & & 2 & 2 & & 2 & 35 & & & & & & 2 & & 2 & 6 & 4 & 55 \\
\hline 13 & & 1 & & & & & & & & & & & & 1 & & 1 & 3 \\
\hline 14 & & & & & & 1 & & & & & & & & & & & 1 \\
\hline 15 & & & & 1 & & 4 & & & & & & & 1 & 11 & 2 & 16 & 35 \\
\hline 16 & & & & & & 1 & & & & & & & & & & & 1 \\
\hline 17 & & & & & & 1 & & & & & & & & & & & 1 \\
\hline 18 & & & & & & & & & & & & & & & & & 0 \\
\hline 19 & & & & & & 7 & & & & & & & & & 1 & & 8 \\
\hline 20 & & & & & & 1 & & & & & & & & & & & 1 \\
\hline 21 & & 4 & 1 & & & & & & & & & & & & & 1 & 6 \\
\hline 22 & & 1 & & & & & & & & & & & & & & & 1 \\
\hline 23 & & & & & & 1 & & & & & & & & & & & 1 \\
\hline 24 & & & & & & 4 & & & & & & & & & & & 4 \\
\hline 25 & & & & & & & & & & & & & & & 1 & & 1 \\
\hline Total & 1 & $\begin{array}{c}27 \\
(5.3) \dagger\end{array}$ & 11 & $\begin{array}{l}15 \\
(2.9)\end{array}$ & 6 & $\begin{array}{l}139 \\
(27.1)\end{array}$ & 3 & 1 & 2 & 11 & 4 & $\begin{array}{c}15 \\
(2.9)\end{array}$ & 1 & $\begin{array}{l}176 \\
(34.4)\end{array}$ & $\begin{array}{l}22 \\
(4.3)\end{array}$ & $\begin{array}{c}78 \\
(15.2)\end{array}$ & $\begin{array}{c}512 \\
(100)\end{array}$ \\
\hline
\end{tabular}

* Rough varients of bacteria.

$\uparrow$ Figures in parentheses indicate percent of total number. 


\section{Discussion}

The bacteriocins produced by various species of bacteria act only on strains of the same or closely related species, and the narrow specificity of their action and their protein nature distinguish them from all other antibiotics. The bacteriocins were first studied by Gratia (1925) who observed growth inhibition between Escherichia coli $\phi$ and $V$ strains, and the name, bacteriocin, was originally used by Jacob et al. (1953). The bacteriocins are designated by species of the strains producing them and those of $S$. marcescens are named marcescins.

The bacteriocins are genetically stable, and they require a specific receptor on the sensitive strain for their adsorption and killing action (Reeves 1965; Nomura 1967). Utilizing these properties, many different bacteriocin typing methods have been investigated to study the distribution of basteria or the epidemiology of infection with gram negative bacilli, such as Shigella sonnei (Abbott and Shannon 1958) or Pseudomonas aeruginosa (Gillies and Govan 1966). Concerning S. marcescens, Farmer (1972a, b) and Traub et al. (1971) described the methods of bacteriocin typing; one was a production (Farmer 1972a) and the other a sensitivity method (Farmer 1972b; Traub et al. 1971). They used liquid culture media with mitomycin $\mathrm{C}$ for induction.

The purpose of this study was to learn how many S. marcescens strains produc ed bacteriocins and the possibility of bacteriocin typing from agar plate cultures without induction reagents, such as mitomycin C.

In the complete checker-board experiment using 80 strains of $S$. marcescens $54 \%$ of them were bacteriocin-producers and $93 \%$ were sensitive to bacteriocins. Only $5 \%$ of the strains did not show any reaction in bacteriocin activity. All of the strains tested were immune to the bacteriocins produced by themselves. Hammon and Péron (1961) first reported that $73(86 \%)$ out of 85 strains tested were bacteriocinogenic. Prinsloo (1966) reported that out of 139 strains tested, $36(26 \%)$ produced group A bacteriocins, 19 (14\%) produced group B bacteriocins, $35(25 \%)$ produced both groups and $49(32 \%)$ did not produce either of them. As it is considered that most strains of $S$. marcescens are bacteriocinogenic, it seems feasible to type them using the bacteriocins.

The bacteriocins produced in this method were considered to be group A bacteriocins (Prinsloo) resembling phage tails, resistant to trypsin, chloroform and heat, and active to the same or closely related species.

The bacteriocin production of $S$. marcescens was unstable in some conditions; temperatures and culture media. It has already been recognized that incubation at low temperature such as $30^{\circ} \mathrm{C}$ is optimal for production of the bacteriocins (Farmer 1972a), and this fact was confirmed in the present study. An appropriate agar medium must be chosen for obtaining consistent results in the bacteriocin typing, because the production of bacteriocins varied with the type of agar media. In the study on reproducibility of the bacteriocin production tests and senstivity tests for the purpose of bacteriocin typing of S. marcescens, the same results could not be obtained in some strains by repeated experiments. 
However, 2 out of 3 trials demonstrated identical results, and it was concluded that bacteriocin typing of $S$. marcescens by this method could be utilized in epidemiological studies.

Farmer $(1972 \mathrm{a}, \mathrm{b})$ classified 129 strains into 72 types in bacteriocin production typing and 93 strains into 70 types in bacteriocin sensitivity typing, and he reported that the latter was less stable as an epidemiological marker than the former. Traub et al. (1971), and Traub and Raymond (1971) used bacteriocin sensitivity typing with a simple, reproducible technique, and classified 179 strains into 37 types. In this study, bacteriocin production typing showed more stable results than bacteriocin sensitivity typing, but the former was less classifiable than the latter. Furthermore it may be necessary to select the appropriate indicators and culture media for typing. One hundred out of 512 S. marcescens strains were not able to be classified into any type in 0 -serotyping, but were classified into 13 types by bacteriocin production typing. Therefore, it was concluded that bacteriocin typing could be used in subdividing the 0 -serotypes of $S$. marcescens, and the epidemiology of $S$. marcescens infections might be better clarified by the use of bacteriocin typing.

\section{Acknowledgments}

Thanks are due to Prof. K. Hara and Prof. T. Usui for their kind suggestions, and to the technologists of the Bacteriological Division of Laboratory Medicine, Nagasaki University Hospital for their assistance in this study.

\section{References}

1) Abbott, J.D. \& Shannon, R. (1958) A method for typing Shigella sonnei using colicine production as a marker. J. clin. Path., 11, 71-77.

2) Anderhub, B., Pitt, T.L., Erdman, Y.J. \& Willcox, W.R. (1977) A comparison of typing methods for Serratia marcescens. J. Hyg. (Camb.), 79, 89-102.

3) Buchanan, R.E. \& Gibbons, N.E. (1974) Bergey's Manual of Determinative Bacteriology, 8th ed. The Williams \& Wilkins Co., Baltimore.

4) Cowan, S.T. (1974) Cowan and Steel's Manual for the Identification of Medical Bacteria, 2nd ed. Cambridge University Press, London.

5) Davis, J.T., Foltz, E. \& Blakemore, W.S. (1970) Serratia marcescens. A pathogen of increasing clinical importance. J. Amer. med. Ass., 214, 2190-2192.

6) Editorial (1977) The importance of $S$. marcescens. Lancet, 1, 636-637.

7) Farmer, J.J., III. (1972a) Epidemiological differentiation of Serratia marcescens: Typing by bacteriocin production. Appl. Microbiol., 23, 218-225.

8) Farmer J.J., III. (1972b) Epidemiological differentiation of Serratia marcescens: Typing by bacteriocin sensitivity. Appl. Microbiol., 23, 226-231.

9) Fuller, A.T. \& Horton, J.M. (1950) Marcescin, an antibiotic substance from Serratia marcescens. J. gen. Microbiol., 4, 413-433.

10) Gillies, R.R. \& Govan, J.R.W. (1966) Typing of Pseudomonas pyocyanea by pyocine production. J. Path. Bact., 91, 339-345.

11) Gratia, A. (1925) Sur un remarquable exemple d'antagonisme entre deux souches de colibacille. Compt. Rend., 93, 1040-1041.

12) Hamon, Y. \& Peron, Y. (1961) Etude de la propriété bactériocinogéne dans le genre Serratia. Ann. Inst. Pasteur, 100, 818-821.

13) Jacob, F., Lwoff, A., Simonovitch, A. \& Wollman, E.L. (1953) Définition de quelques terms relatifs á la lysogénie. Ann. Inst. Pasteur, 84, 222-224. 
14) Nasu, M. (1977) Study on Bacteriocin (marcescin) typing of Serratia marcescens. $J$. Jap. Ass. infect. Dis., 51, 487-498. (Japanese)

15) Nasu, M., Sawatari, K., Mochida, C., Iori, F., \& Hayashi, A. (1977) Isolation of genus Serratia in clinical materials. Jap. J. clin. Path., 25, 325-328. (Japanese)

16) Nomura, M. (1967) Colicins and related bacteriocins. Ann. Rev. Microbiol., 21, 257284.

17) Prinsloo, H.E. (1966) Bacteriocins and phages produced by Serratia marcescens. $J$. gen. Microbiol., 45, 205-212.

18) Reeves, P. (1965) The bacteriocins. Bacteriol. Rev., 29, 24-45.

19) Traub, W.H. \& Raymond, E.A. (1971) Epidemiological surveillance of Serratia marcescens infections by bacteriocin typing. Appl. Microbiol., 22, 1058-1063.

20) Traub, W.H., Raymond, E.A. \& Startsman, T.S. (1971) Bacteriocin (Marcescin) typing of clinical isolates of Serratia marcescens. Appl. Microbiol., 21, 837-840.

21) Yu, V.L. (1979) Serratia marcescens. Historical perspective and clinical review. New Engl. J. Med., 300, 887-893. 